\title{
Collaborative Design and Implementation of a Multisite Community Coalition Evaluation
}

\author{
Laurie L. Lachance, $\mathrm{PhD}, \mathrm{MPH}$ \\ Christy R. Houle, MPH \\ Elaine F. Cassidy, PhD \\ Emily Bourcier, MPH, MHA \\ Jennifer H. Cohn, MLS \\ Carlyn E. Orians, MA \\ Kathleen Coughey, $\mathrm{PhD}$ \\ Xin Geng, MS \\ Christine L. M. Joseph, $\mathrm{PhD}$ \\ Michael D. Lyde, PhD \\ Linda Jo Doctor, MPH \\ Noreen M. Clark, PhD
}

Evaluation designs assessing community coalitions must balance measures of how coalitions do their work and evidence that the coalitions are making a difference. The Allies cross-site evaluation attempts to determine the combined effects of the seven coalitions' work at the individual, organizational, and community levels. Principal components considered are (a) contextual factors of the coalition community, (b) coalition processes and structure, (c) planning and planning products, (d) implementation actions, (e) activities and collaborations, ( $f$ ) anticipated intermediate outcomes, and (g) expected asthma related health outcomes. Measurements are quantitative and qualitative, and data generated by these methods are used as ends in themselves and as a way to confirm or inform other measures. Evaluation has been an integral part of the planning and implementation phases of the Allies coalition work, with a priority of involving all of the partners in conceiving of and deciding upon the elements of assessment.

Keywords: evaluation; coalitions; asthma

Health Promotion Practice

Supplement to April 2006 Vol. 7, No. 2, 44S-55S

DOI: $10.1177 / 1524839906287066$

(C2006 Society for Public Health Education
$\mathrm{T}$ The purpose of this article is to describe the design and implementation of the Robert Wood Johnson Foundation's (RWJF) Allies Against Asthma crosssite evaluation. The Allies Against Asthma (Allies) program consists of seven coalition sites, each comprising various stakeholders such as local health care providers, schools and day care centers, community advocacy groups, businesses, local government organizations, managed care organizations, academic institutions, parent groups, and other community-based organizations, which aim to combat pediatric asthma. The evaluation approach for Allies was designed collaboratively by

Editors' Note: This article is part of a special supplement of Health Promotion Practice that describes the development and implementation of the Allies Against Asthma (Allies) initiative. Funded by the Robert Wood Johnson Foundation with direction and technical assistance provided by the University of Michigan School of Public Health, Allies provides support to seven community-based coalitions nationwide to develop, implement, and sustain comprehensive asthma management programs. Through Allies, each coalition received grants totaling approximately US $\$ 1.5$ million to support the coalition, its targeted activities, and evaluation for 1 year of planning and 3 to 4 years of implementation. The supplement describes the first phase of the initiative, during which coalitions designed and implemented a range of activities including improved access to and quality of medical services; education, family, and community support; and environmental and policy initiatives. More information about the initiative and tools and materials developed by the coalitions can be found at www.AlliesAgainstAsthma.net. 


\section{The Authors}

Laurie L. Lachance, $P h D, M P H$, is the evaluation director of Allies Against Asthma, associate of the Center for Managing Chronic Disease, and an assistant research scientist in health behavior and health education at the University of Michigan in Ann Arbor, Michigan.

Christy R. Houle, MPH, is a program manager of the Allies Against Asthma National Program Office and a predoctoral candidate in health education and behavior at the University of Michigan School of Public Health in Ann Arbor, Michigan.

Elaine F. Cassidy, PhD, is a program officer in Research and Evaluation at the Robert Wood Johnson Foundation in Princeton, New Jersey.

Emily Bourcier, $M P H, M H A$, is the evaluation coordinator of the King County Asthma Forum (KCAF) and a program manager with the Evaluation Team at Group Health Community Foundation in Seattle, Washington.

Jennifer H. Cohn, MLS, is the surveillance and evaluation coordinator of Fight Asthma Milwaukee Allies (FAM Allies) and a program coordinator in the Department of Pediatrics at the Medical College of Wisconsin in Milwaukee, Wisconsin.

Carlyn E. Orians, $M A$, is an evaluation consultant for Allies Against Asthma and a senior research scientist at Battelle Centers for Public Health Research and Evaluation in Seattle, Washington.
Kathleen Coughey, PhD, is an evaluator for Philadelphia Allies Against Asthma (PAAA) and a senior research associate at the Philadelphia Health Management Corporation in Philadelphia, Pennsylvania.

Xin Geng, MS, is the former data specialist of Allies Against Asthma at the University of Michigan School of Public Health in Ann Arbor, Michigan.

Christine L. M. Joseph, $P h D$, is an evaluation consultant of Allies Against Asthma and a research epidemiologist at the Henry Ford Health System in Detroit, Michigan.

Michael D. Lyde, PhD, is the evaluation consultant for the Long Beach Alliance for Children with Asthma (LBACA), an adjunct professor in Psychology and Health Sciences at California State University Dominguez Hills in Carson, CA, and an adjunct professor in professional studies at California State University Long Beach in Long Beach, California.

Linda Jo Doctor, MPH, is the former deputy director of Allies Against Asthma at the University of Michigan School of Public Health and a program director for health at the W.K. Kellogg Foundation in Battle Creek, Michigan.

Noreen M. Clark, PhD, is the director of Allies Against Asthma; Marshall H. Becker professor of public health; director of the Center for Managing Chronic Disease; and professor of pediatrics and communicable diseases at the University of Michigan in Ann Arbor, Michigan. leaders from all seven asthma community coalitions, the program's National Advisory Committee (NAC) members, and the Allies National Program Office (NPO) staff.

The history of community-based health promotion programs reflects a slow but steady movement from externally imposed, standardized, narrowly focused interventions to community-driven, comprehensive approaches. The earliest community-based health initiatives used traditional health education interventions-for example, targeting heart disease with media campaigns and smoking cessation classes (COMMIT Research Group, 1995; Farquhar et al., 1990; Green, 1992; Tarlow et al., 1987).

Recent community-based initiatives have taken a broader perspective, viewing many dimensions of life in a community as either aspects of community health or potential building blocks for community health improvement (Beery et al, 2005; El-Askari et al., 1998; Wallerstein, 1999). There is some evidence in the literature (Butterfoss, Goodman, \& Wandersman, 1993; Merzel \& D'Afflitti, 2003) that ensuring community members identify community needs is crucial and leads to increases in capacity of community systems, improved quality of life, and community-specific outcomes. Community-based strategies that focus on populations have the ability to achieve a public health impact on rates of disease (Merzel \& D’Afflitti, 2003; Rose, 1992).

\section{BACKGROUND}

Evidence during the past 20 years suggests that community-based coalitions have had weak or modest impact on decreasing population-level risk behavior (Merzel \& D'Afflitti, 2003) and promoting communitylevel health change (Kreuter, Lezin, \& Young, 2000). It is important to note, however, that methodological obstacles almost surely account for some of the lack of evidence on coalition effectiveness (Berkowitz, 2001). The existing literature on community-based coalitions cites several evaluation challenges faced by coalitions, including those that focus on single health targets, such as improved health outcomes for children with asthma (Koepsell et al., 1991; Koepsell et al., 1992). These 
obstacles can make it difficult to gather high-quality data, which in turn can impede the overall quality of the evaluation attempt.

One of the primary obstacles in conducting a highquality evaluation of coalition work is that measurement of outcomes is often overlooked in planning and funding (Butterfoss \& Francisco, 2004). Because evaluations are often underresourced they may be too short in duration to assess long-term impact (Kegler, Steckler, McLeroy, \& Malek, 1998; Lasker \& Weiss, 2003; Ruossos \& Fawcett, 2000). As a result, evaluators often focus on formative and process assessments (Mittlemark et al., 1986) rather than outcomes.

The engagement of community members is increasingly considered important to the quality of the evaluation of community-based coalition efforts (Schlaff, 1991). Evaluators who successfully connect with community members are more likely to develop relevant data collection tools and to gain credibility in the community. This credibility may help encourage broader participation in data collection efforts (Bracht, 1990). Those who do not successfully involve community members run the risk of obtaining data that lacks validity because it fails to reflect true feelings or actions (Peterson et al., 2006 [this issue]).

Another challenge in evaluating coalitions is the lack of pertinent theory available to explain the mechanisms producing coalition outcomes (Lasker \& Weiss, 2003; McLeroy, Norton, Kegler, Burdine, \& Sumaya, 2003; Ruossos \& Fawcett, 2000). Given that most health promotion theories focus on individual behavior change as opposed to group behavior (Merzel \& D'Afflitti, 2003), this lack of fit between theory and evaluation approaches can impede evaluators' abilities to illustrate the links between outcomes of specific strategies and a communitywide impact (McLeroy et al., 2003).

Other challenges are more methodological in nature. Many studies of community-based coalitions cannot implement true experimental designs, random assignment (Merzel \& D'Afflitti, 2003), and/or control groups (Lasker \& Weiss, 2003; Ruossos \& Fawcett, 2000). In some cases, it may be logistically or otherwise difficult to obtain a suitable comparison group (McLeroy et al., 2003). If a comparison group is not available, evaluators sometimes use a pre- and postdesign collecting data before and after coalitions are put in place. Such withinsite comparisons may provide some helpful information about the intervention used but cannot account for other factors that may have produced the change observed nor for secular trends. Selection bias may occur in studies of community-based coalitions because those who participate in them may not represent the larger community (Berkowitz, 2001; Merzel \& D’Afflitti, 2003). Careful planning is needed to reduce these potential obstacles in evaluating the impact of a community coalition.

\section{ALLIES AGAINST ASTHMA EVALUATION DESIGN}

The Allies evaluation design attempted to overcome, to the extent possible, the obstacles described above. Efforts include the use of quantitative and qualitative research methods and investigation of coalition processes and outcomes. Multimethod approaches are thought to allow for a fuller understanding of complex programs, recognizing that different methods are either better suited to understanding certain aspects of a phenomenon or provide more than one perspective on the same aspect of a phenomenon (Barbour, 1999; Brewer \& Hunter, 1989; Denzin, 1970; Patton, 2001; Sandelowski, 2000).

The Allies cross-site evaluation uses the framework presented in an accompanying article by Clark et al. (2006 [this issue]) as the basis for conceptualizing evaluation objectives and processes. The use of qualitative and quantitative methods is an attempt to capture a range of individual and environmental factors that can influence behaviors and health, including individual, institutional, community, and public policy factors.

Questions for the Allies cross-site evaluation include determining how processes, functions, structures, and outcomes were the same or different across various coalitions. In particular, the Allies evaluation examines the interrelationships among stages of coalition development, factors influencing optimal coalition functioning and attainment of outcomes, and how these factors may interact with different types and sizes of coalitions. Using common measurements over time to understand factors related to coalition processes and structures, and the planning and implementation of activities, may provide information that can enhance the development and sustainability of coalitions, and help improve their ability to influence intermediate and longer term outcomes.

The Allies cross-site evaluation is attempting to determine the combined effects of the coalitions' work at the individual, organizational, and community levels. Process and outcome-related data are collected by the local sites and submitted to the NPO at the University of Michigan for cross-site analyses. In addition, several local sites are conducting their own evaluations that assess factors beyond those included in the national cross-site evaluation.

An evaluation group comprising leaders from each coalition, expert members of the NAC, and NPO staff and consultants used open discussions to determine the evaluation design and methods (see Appendix A for a list of NAC members and NPO staff). Each coalition 


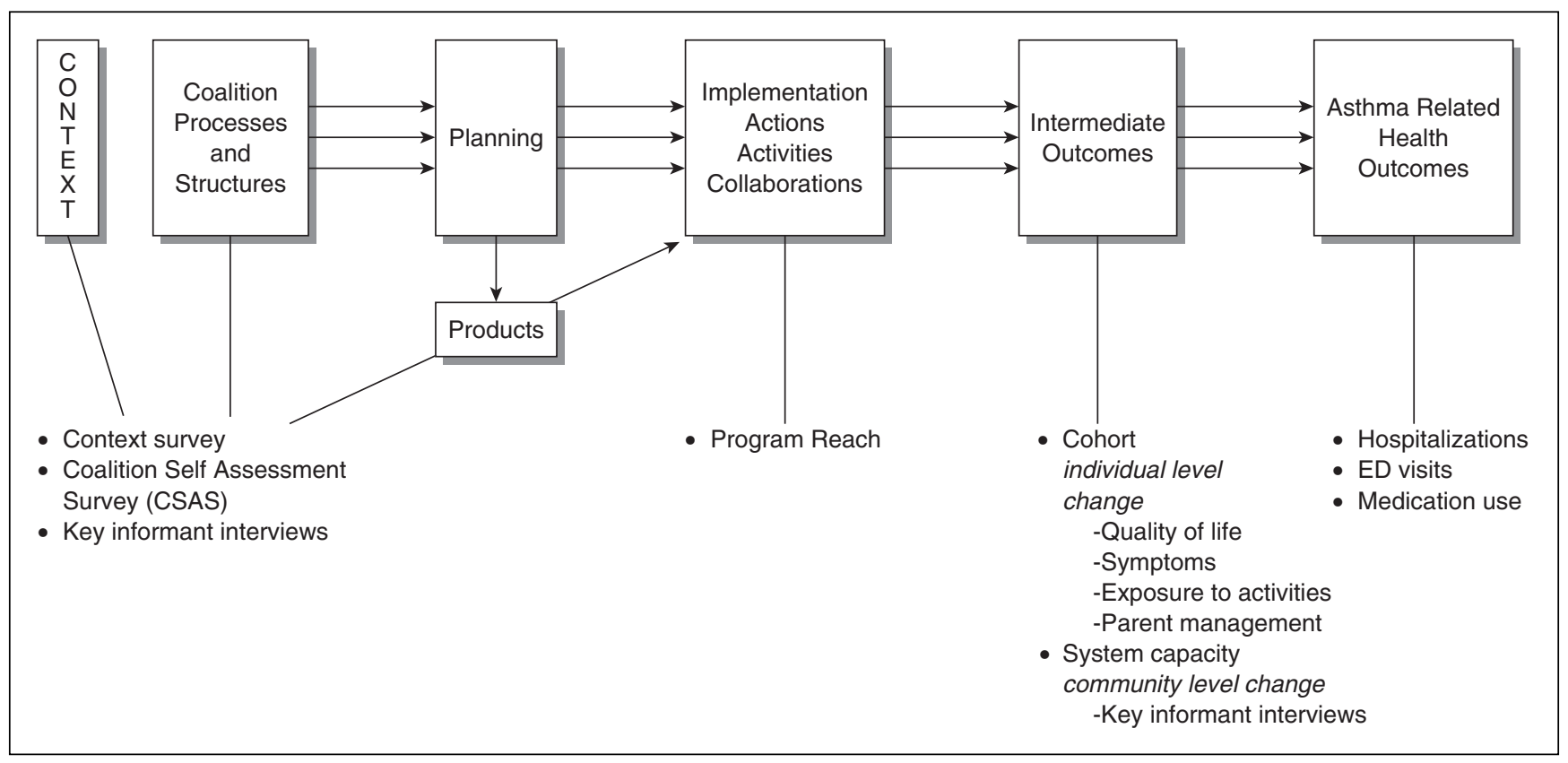

FIGURE 1 Allies Against Asthma Cross-Site Evaluation

explored how and why specific instruments or data collection techniques would or would not be appropriate for their sites. These explorations and discussions took place throughout the planning and implementation periods through periodic face-to-face meetings in which all coalitions were represented, and through individual discussions and conference calls. The full evaluation group's first discussion, conducted shortly after coalitions were approved for implementation funding, early in the 1st year of implementation, focused on the evaluation framework. Based on a review of the literature and consideration of coalition goals and objectives, the logic of the evaluation was developed (see Figure 1). This model serves as the basis for decisions related to evaluation design, method, and measures. The principal components include (a) contextual factors related to the community where the coalition operates, (b) coalition processes and structures, (c) planning and planning products, (d) implementation actions, (e) activities and collaborations, (f) anticipated intermediate outcomes, and $(\mathrm{g})$ expected asthma related health outcomes.

Subsequently, potential instruments and measures were discussed within the evaluation group and examined by individual sites. Factors for consideration included (a) cultural relevance, (b) potential for translation, (c) feasibility of data collection requirements, (d) fit with data collection timelines, (e) appropriate literacy levels, and (f) types (quantitative and/or qualitative) and quality of data generated.

To be sensitive to the diverse populations involved, accommodate program needs, and recognize political considerations in local sites, the final evaluation design and method included only those elements for which there was consensus. A flexible start-up period for data collection was agreed on, thereby allowing time for coalitions to negotiate with local partners and stakeholders. Where necessary, translation of instruments to Spanish was a joint effort of coalition members and consultants with expertise in Spanish dialects.

\section{Logic of the Allies Cross-Site Evaluation}

In this section the components of the Allies evaluation as presented in Figure 1 are discussed in light of the overall evaluation design and the ultimate choice of assessment methods. The following section describes the data collection processes and methods of analysis.

Coalition context. The Allies coalitions differ widely in their geographic locations and community context. Coalitions are embedded in communities, and because of this it is important to evaluate them in light of the characteristics of the given community. These 
characteristics can have a significant impact on the coalition not only during the early phases of development but also throughout all stages of its functioning (Butterfoss et al., 1993; Lasker, Weiss, \& Miller, 2001; McLeroy, Kegler, Steckler, Burdine, \& Wisotzky, 1994). Influences that will affect the coalition's functioning and success include the cultural, political, and economic environment of the community; the history of collaboration; the presence of other coalitions; degree of cooperation and conflict among community agencies, geography, population diversity; and economic climate (Butterfoss \& Kegler, 2002; Clark et al., 2006 [this issue]; Kenney \& Sofaer, 2000; Lasker et al., 2001; McLeroy et al., 1994; Roussos \& Fawcett, 2000; Wolff, 2001). Community readiness or preparedness for collaboration is another important dimension of community context and involves the ability of the community to take on its tasks and find ways to solve its own problems, usually involving multiple sectors (Wolff, 2001). Community attitudes, motivation to form a coalition, quality of available leaders, existing mechanisms for individuals and organizations to participate in local problem solving, and opportunities for funding influence development of a coalition (Lasker et al., 2001; McLeroy et al., 1994; Roussos \& Fawcett, 2000; Wolff, 2001). As part of the Allies cross-site evaluation, coalition leadership are interviewed at several time points throughout planning and implementation phases to document contextual factors.

Coalition processes and structures. Butterfoss, Goodman, and Wandersman (1996) examined factors that could help a coalition effectively maintain itself over time. The key elements identified include competent leadership, shared decision making, linkages with other organizations, and a supportive environment. They also noted that coalitions with these attributes are more likely to perceive that the benefits of participation outweigh the costs and also will produce members who are more participative in the work of the committees and other task groups of the coalition. Effective internal functioning in coalitions is necessary for progress in achieving coalition goals (Butterfoss \& Kegler, 2002). Characteristics of coalitions that are being measured in the Allies evaluation include decision making and the extent to which members have decision-making influence; the extent of conflict and conflict resolution; members' perceptions of the coalition leadership, including the ability of the leadership to build consensus on key decisions and get things done; management expertise, including the work of the paid staff; the extent of trust among coalition members and the perception of members about whether they feel their opinion is listened to and considered by others; the extent of shared vision among members; communication patterns; and the extent and allocation of resources available (Kenney \& Sofaer, 2000). The creation of clear structures involves establishing steering and governance committees, task forces, or other entities and finding ways to share decision making across these groups, the membership, outside funders, and the lead agency. Clarifying the roles and responsibilities for each of these groups is considered to be important (Wolff, 2001). Coalition structure includes standing committees and task forces, and the presence and degree of use of formal bylaws, rules of procedure, and decision making. The range of skills, resources, credibility, and perspectives of the coalition's members influences its structure. Ongoing engagement of a broad section of community representatives in active coalition membership and continuous development of the knowledge and skills needed to build an ongoing effective structure are associated with coalition success (FosterFishman, Berkowitz, Lounsbury, Jacobson, \& Allen, 2001; Kegler et al., 1998).

Coalition processes and structures are measured quantitatively and qualitatively in the Allies evaluation. The Coalition Self-Assessment Survey (CSAS) is administered annually to the coalition membership, and key informant interviews are conducted with coalition members, staff and leadership, and community members outside of the coalition. These measures are described more fully in the following section.

Planning and planning products. Planning products articulate strategies and responsibilities for accomplishing coalition goals and include the ways in which the coalition monitors progress and periodically reviews and revises its work priorities (Foster-Fishman et al., 2001). High-quality plans are associated with competent staffing, leadership, and resource mobilization; contribute to successful implementation; and have a subsequent impact on health outcomes (Butterfoss \& Kegler, 2002; Kegler et al., 1998; Kumpfer, Turner, Hopkins, \& Librett, 1993). The Allies cross-site evaluation is assessing the quality of action plans using criteria that include (a) how representative the plan is of the coalition's mission, (b) its clarity and comprehensiveness, (c) the degree to which it anticipates opportunities and barriers for change, (d) the extent to which responsibility for carrying out each step of the action plan is indicated, (e) how it engages diverse stakeholders, (f) how feasible the timeline is, (g) the adequacy of resources allocated, (h) if there is ongoing review of the plan by the coalition members, (i) and dissemination of written plans within the coalition (Ayre, Clough, \& Norris, 2000; Butterfoss 
et al., 1996; KU Work Group on Health Promotion and Community Development, 2000; Roussos \& Fawcett, 2000; Winer \& Ray, 2000).

Implementation activities and collaboration. Coalitions undertake a range of activities to implement an action plan. These might include training, advocacy, education programs, care coordination strategies, home visiting programs, environmental interventions, policy work, quality improvement activities, and community awareness initiatives. The likelihood of achieving desired outcomes depends on the extent to which activities are implemented and reach the priority populations (Butterfoss \& Francisco, 2004).

How well a coalition is able to implement activities is also thought to be associated with the extent to which participants are involved, satisfied, loyal, committed, and contributing to the coalition's work. Coordination and linking of the chosen activities are deemed essential to effective coalition functioning. Indeed, coordination is the added value of a coalition working across the community (Rosenthal et al., 2006 [this issue]).

Each Allies coalition implemented a unique combination of activities that included patient and provider education, assessment and remediation of asthma environmental triggers, quality improvement initiatives, and/or system and policy change efforts. A brief description of each coalition's primary interventions can be found in Appendix B, and a summary table found in the accompanying article by Clark et al. (2006). Data regarding these activities have been gathered throughout the implementation period using Program Reach, a computerized Web-based tracking system, as described more fully below.

Intermediate outcomes. Implementation at multiple levels in the community can create changes at the individual and community levels (Butterfoss \& Kegler, 2002; Fawcett et al., 1997; Goodman, Wandersman, Chinman, Imm, \& Morrisey, 1996; Kegler, Twiss, \& Look, 2000). Individual-level changes include changes in asthma management within families. Community-level changes include coordination and integration of services and creation of new services and structures in the community and indicate maturity of coalition development and progress toward community-wide change in health care provision and health status outcomes (Goodman et al., 1996; Kreuter et al., 2000).

In the Allies evaluation, individual-level changes were defined broadly and include exposure to asthmarelated activities, parent management of asthma, and changes in quality of life and asthma-related symptoms. To measure these changes, each site recruited a cohort of children affected by pediatric asthma that were expected to participate in the coalition's primary interventions, as well as a comparison group. Comparison groups encompass children with asthma outside of the coalition's primary target area who are similar to those exposed to the interventions, demographically and with respect to asthma prevalence, but are not likely to be exposed to the coalition's most intensive interventions. Both groups are being followed for 1 year between measurements.

Community-level changes include improvements to system-level function and changes in system capacity. Examples of activities coalitions are employing to reach such changes include standardization of asthma action plans, protocols, and referral processes; tracking systems and registries; policy changes; quality improvement; and system integration and linkage. These changes reflect health care system and provider-level changes. Such activities are tracked through the Program Reach Web-based system. The results of such efforts, including system capacity changes and coalition impact in the community, will also be measured qualitatively through key informant interviews with coalition members, staff and leadership, as well as key community leaders outside of the coalition, as described in the following section.

Asthma-related health outcomes. The broad aim of Allies is to improve population-level outcomes associated with asthma morbidity. These are defined as reductions in asthma-related hospitalizations, emergency department (ED) visits, and medication use. As noted previously, this level of evidence is often difficult to acquire due to the fact that visible changes in population-level health outcomes may take longer than the lifetime of an evaluation (Roussos \& Fawcett, 2000). Allies is working in partnership with the Center for Medicare and Medicaid Services (CMS) and the Agency for Healthcare Research and Quality/ Healthcare Cost and Utilization Project (AHRQ/HCUP) to obtain and analyze health care utilization data for the Allies sites and comparison communities for the periods before, during, and after RWJF Allies funding. The Center for Medicare and Medicaid Services is providing annual zip code-level data related to Medicaid-supported hospitalizations, ED visits, and medication use for the period 1999 to 2007. The Agency for Healthcare Research and Quality is providing hospitalization data for this same time period supported by multiple payers. Additional details regarding this data and planned analyses are discussed below.

\section{Data Analysis}

The Allies analysis plan includes assessments at the coalition, individual, and community levels. The 
TABLE 1

Measures of the Allies Against Asthma Cross-Site Evaluation

\begin{tabular}{|c|c|c|c|}
\hline Measure & Sample & Outcome & Administration \\
\hline Context Survey & Coalition leadership & $\begin{array}{l}\text { Coalition context } \\
\text { and structure }\end{array}$ & $\begin{array}{l}\text { During baseline and follow-up } \\
\text { for Coalition Self-Assessment } \\
\text { Survey data collection time } \\
\text { period }(2002,2004,2005)\end{array}$ \\
\hline $\begin{array}{l}\text { Coalition Self-Assessment } \\
\text { Survey (CSAS) }\end{array}$ & $\begin{array}{l}\text { Coalition members } \\
\text { and staff }\end{array}$ & $\begin{array}{l}\text { Coalition processes } \\
\text { and planning }\end{array}$ & $\begin{array}{l}\text { Annual administration } \\
\text { (2002-2005) }\end{array}$ \\
\hline Key Informant Interviews & $\begin{array}{l}\text { Coalition members, } \\
\text { leaders, and outside } \\
\text { community }\end{array}$ & $\begin{array}{l}\text { Coalition process } \\
\text { and intermediate } \\
\text { outcomes, } \\
\text { community-level } \\
\text { asthma management } \\
\text { changes }\end{array}$ & $\begin{array}{l}\text { Baseline and follow-up } \\
\quad(2003,2005)\end{array}$ \\
\hline Program Reach & Coalition staff & $\begin{array}{l}\text { Coalition } \\
\text { implementation } \\
\text { actions and } \\
\text { collaborations }\end{array}$ & $\begin{array}{l}\text { Continuous with quarterly } \\
\text { reporting (2003-2005) }\end{array}$ \\
\hline $\begin{array}{l}\text { Core Caregiver Survey } \\
\text { (Cohort) } \\
\text { Caregiver Quality of Life } \\
\text { Asthma symptoms } \\
\text { Hospitalizations and } \\
\text { ED visits (self-report) } \\
\text { Exposure to asthma- } \\
\text { related activities } \\
\text { Parent asthma } \\
\text { management strategies }\end{array}$ & $\begin{array}{l}\text { Cohort of families } \\
\text { with asthma within } \\
\text { the intervention } \\
\text { target area of the } \\
\text { coalition }\end{array}$ & $\begin{array}{l}\text { Intermediate } \\
\text { outcomes, } \\
\text { individual-level } \\
\text { asthma } \\
\text { management }\end{array}$ & $\begin{array}{l}\text { Baseline and follow-up (rolling } \\
\text { enrollment 2003-2006) }\end{array}$ \\
\hline $\begin{array}{l}\text { Asthma-related } \\
\text { hospitalizations } \\
\text { AHRQ/HCUP, CMS }\end{array}$ & $\begin{array}{l}\text { Zip code areas of } \\
\text { coalitions and } \\
\text { comparison } \\
\text { communities }\end{array}$ & $\begin{array}{l}\text { Asthma-related } \\
\text { health outcomes }\end{array}$ & Annual rates from 1999 to 2007 \\
\hline $\begin{array}{l}\text { Asthma-related ED visits } \\
\text { and medication use } \\
\text { CMS }\end{array}$ & $\begin{array}{l}\text { Zip code areas of } \\
\text { coalitions and } \\
\text { comparison } \\
\text { communities }\end{array}$ & $\begin{array}{l}\text { Asthma-related } \\
\text { health outcomes }\end{array}$ & Annual rates from 1999 to 2007 \\
\hline $\begin{array}{l}\text { Comparison Communities } \\
\text { Survey }\end{array}$ & $\begin{array}{l}\text { Key informants: } \\
\text { Asthma stakeholders } \\
\text { in comparison } \\
\text { communities }\end{array}$ & $\begin{array}{l}\text { Asthma-related } \\
\text { activities in } \\
\text { comparison } \\
\text { communities }\end{array}$ & $\begin{array}{l}\text { Annual retrospective reports } \\
\quad(2000-2005) \text {, final report } 2006\end{array}$ \\
\hline
\end{tabular}

NOTE: ED = emergency department; AHRQ/HCUP = Agency for Healthcare Research and Quality/Healthcare Cost and Utilization Project; CMS $=$ Center for Medicare and Medicaid Services.

primary goals of the analyses are to (a) describe the coalitions in terms of context, structure, and process; (b) describe the frequency and quality of coalition plans and activities in relation to coalition context, structure, process, and outcomes; (c) analyze differences between the intervention and comparison groups regarding 
asthma-related symptoms, self-report of hospitalizations and ED visits, caregiver quality of life, and asthma management strategies, and also changes for these groups between baseline and follow-up; (d) describe asthma management changes at the community level, including coalition impact and system capacity changes; and (e) assess differences in coalition sites and comparison communities regarding health care use as evident in Medicaid and AHRQ data.

Table 1 provides a summary of the measures used in the Allies cross-site evaluation. These measures address each of the components described in the logic model (see Figure 1).

Context Survey. The Context Survey provides quantitative and qualitative information about coalition structure and functioning, the focus of coalition efforts, and also information about the social, cultural, and political environment of the community in which the coalition operates. The survey is a semistructured telephone interview conducted by the NPO staff with one to three coalition members and staff from each of the seven sites. Context surveys were conducted at baseline with a second administration 2 years later to coincide with the time frame of the Coalition Self-Assessment Survey (CSAS) administration. Data from the context interviews will also be used to help interpret responses related to coalition processes from CSAS. Analysis includes content analysis of coalition structure, community readiness, and lessons learned by the coalitions.

CSAS Survey. The Coalition Self-Assessment Survey (CSAS) is administered annually to the coalition membership to capture quantitative information on coalition structure and processes, including coalition functioning, leadership, and effectiveness of effort. The original survey developed by Kenney and Sofaer (2000) was modified by the Allies evaluation group (see Appendix C for access to the CSAS instrument). The survey is administered by local staff at a general membership meeting or via U.S. mail to members who have attended at least two coalition meetings within the 12 months prior to the survey.

CSAS results are reported to the Allies sites from the NPO annually and include site-specific information along with ranges of responses from all sites combined. CSAS responses from all sites are combined and analyzed descriptively, and bivariate relationships are explored, stratified by role in coalition, site, and other demographic variables. Reliability analysis of questions from CSAS using categories based on previous factor analyses by Kenney and Sofaer (2000) are used to formulate indices for further descriptive analysis, bivariate analysis, and regression model building. Articles in this issue by Butterfoss et al. (2006), Peterson et al. (2006), Kelly et al. (2006), and Krieger et al. (2006) provide current CSAS results.

Key informant interviews. Key informant interviews were conducted by a neutral contractor at two points in time (baseline [2003] and follow-up [2005]) with a selected number of coalition staff and leaders, coalition members, and community leaders. Key informants inside and outside the coalition were selected based on their relationship to the coalition, history within the community, professional backgrounds, and personal connections to asthma. Interviews with 15 to 17 individuals from each site were intended to provide a broad range of perspectives on the activities of each coalition. Interview guides and key informant selection protocols were developed collaboratively with input from each coalition and the NPO staff. The semistructured interviews were designed to collect information from the point of view of participants in their own words about the coalition planning process, level of their involvement in the coalition, goals and interventions, and perceptions of coalition impact. The follow-up interviews also address change in coalition structure and membership, implementation of interventions, and progress toward goals, including the individual's satisfaction with the interventions currently being implemented and perceptions of collaborations and linkages among community-based organizations. The baseline and follow-up interviews address participants' expectations about future outcomes and their perspectives on the value added of the coalition.

The electronic records of interview data were sorted by codes based on study questions and themes to analyze each specific topic qualitatively. Coded data for each site were analyzed independently. A summary report for each site was prepared by the contractor for baseline and follow-up based on the interview data and any documents collected and reviewed. The site-specific reports were reviewed by each site for accuracy and completeness before they were submitted to the NPO. Articles in this issue by Butterfoss et al. (2006) and Butterfoss, Lachance, and Orians (2006) provide current data from the key informant interviews.

Program Reach. Program Reach captures processoriented data on the extent of coalition activities. It is a password-protected, Web-based, site-specific tracking system. Local coalition staff enter data to describe the activities conducted including the zip code area where the activity took place. The database also includes the number and type of program participants, topics addressed, settings in which activities were conducted, 
and system changes implemented. Program Reach data for all sites are compiled by the NPO staff and will be examined to identify depth and breadth of program activities. For example, home visit programs will be described according to number of visits and content of visits, including asthma education, environmental assessment, and care coordination. Types of overall activities will be described along with how these activities varied over time and by coalition. Program Reach data collection is ongoing; analysis will be conducted after the implementation period.

Core Caregiver Survey. The Core Caregiver Survey is a key feature of the intermediate outcomes assessment. The instrument contains multiple measures for assessment of children with asthma in the intervention and local comparison communities. The survey includes the Pediatric Asthma Caregiver Quality of Life Questionnaire (Juniper et al., 1996), which asks about ways a child's asthma has interfered with the caregiver's normal daily activities and how this has made she or he feel. Questions related to the child's daytime and nighttime asthma symptoms included in the survey are adapted from the National Cooperative Inner-City Asthma Study (Evans et al., 1999). The Core Caregiver Survey also includes self-report of hospitalizations and ED visits, and, in some sites, information about parent asthma management strategies (Clark et al., 1986). The adapted survey also elicits information on the exposure of children and families to specific coalition asthmacontrol activities (Fisher, Strunk, Sussman, Sykes, \& Walker, 2004; Fisher et al., 1994; Fisher et al., 1996). The Core Caregiver Survey is administered at baseline and at a 1-year follow-up to a cohort of individuals exposed to the coalition's most intensive interventions.

Follow-up data collection will continue throughout the coming year. When in hand, the NPO will conduct baseline to follow-up analyses for intervention and comparison groups collectively and for each coalition site. Our analysis will pool data across the coalition sites taking into account any differences between intervention and comparison groups at each site. Although variability exists among the sites in race and ethnicity composition, age ranges, time frames, and interventions, pooling of the data is feasible because all of the coalition sites used the same measures and focused on populations where asthma prevalence is the highest. Analysis of pooled data will include stratification and control for coalition site. Bivariate relationships will be explored between items in the Core Caregiver Survey. In particular, relationships between factors related to symptoms, health care utilization, and quality-of-life outcomes will be investigated. Multilevel models will be constructed adjusting for site differences in treatments, individuals participating in the study, and study site characteristics.

Asthma-related health care utilization. Health care utilization will be analyzed for hospitalizations, ED visits, and medication use in zip code areas related to the coalition intervention and comparison communities. Each Allies coalition submitted targeted zip codes in which their site-specific intervention activities are expected to have the most impact. For each Allies zip code, the NPO staff, with coalition participation, identified one or two demographically similar comparison zip codes (according to Census 2000 data) to serve as comparison communities. Demographic characteristics focus on race and median income, as these variables consistently are associated with asthma prevalence. Secondary variables used in the selection included total population, percentage of family households, and percentage of the population younger than age 18 years.

Hospitalizations will be analyzed from two separate data sources. First, hospitalizations will be extracted from Medicaid data for the period 1999 to 2007 to look at change over time in coalition and comparison communities. Hospitalization rates will be calculated using year 2000 census data as the reference population for each zip code area. Hospitalizations will also be calculated using HCUP data, which represents Medicaid, commercial, uninsured, and other payers. These data will be calculated into rates and compared between intervention and comparison sites. Because the HCUP data includes individuals who have different insurance payers, this data will also be analyzed according to insurance payer.

Comparison Communities Survey. The Comparison Communities Survey is conducted to ensure similarity of the Allies communities and the comparison sites used for the asthma health-related outcome component. An ideal comparison community would have no coalition-related asthma activity and minimal, if any, community-wide asthma programs. However, such a condition is unlikely to exist, and it is necessary, therefore, to assess the presence of community-wide asthmarelated interventions or activities. Through contacts with state-level asthma control offices, local American Lung Association program directors, and local health departments, the NPO identifies two to three key individuals in each comparison community who are well informed about asthma. Identified persons are asked a series of questions by phone to ascertain the nature and extent of asthma activities in their community. These communities will be coded as high, medium, or 
low asthma activity sites in relation to the level of asthma-related activities and level of linkages among activities and programs.

\section{DISCUSSION}

Evaluation has been an integral part of the planning and implementation phases of the Allies coalition work, with a priority of involving all of the partners in conceiving of and deciding on the elements of assessment. Recognizing that determination of evaluation concepts and early details of instrument development should be fully participatory, Allies started these processes earlyas soon as coalitions were approved for implementation funding. We learned, however, that it is never too early. We also learned that it is essential to build in time to accommodate the changes that inevitably occur in natural settings such as communities. The evaluation design had to be flexible and involve diverse measures to be resilient to change. Furthermore, it takes a great deal of time to develop relevant instruments and prepare translations of those instruments. Allies used a consensus model to design the evaluation framework. Because the coalitions have different levels of evaluation expertise and also are at different levels of coalition development, reaching consensus was a more challenging approach than, for example, predetermining the design and instruments. Each coalition implemented the interventions that were most relevant for their community and appropriate to the expertise within the coalition. The heterogeneity of coalition activity is an obstacle to conventional evaluation designs and makes it difficult to draw conclusions about which specific activities may have contributed to outcomes observed. However, the heterogeneity of intervention strategies and other coalition activities is a strength of the Allies program, in that it allows for pragmatic examination of coalition effectiveness.

Deciding to use comparison groups for measuring intermediate outcomes at the individual level took a great deal of discussion and considerable give-and-take within the evaluation group. And although comparison zip code areas were identified to evaluate health care utilization, given the rise in asthma prevalence and resulting rise in asthma programs, there is no doubt that some form of asthma-related health promotion activity is occurring in all the comparison zip code areas. This increases the difficulty in showing differences attributable to Allies coalitions.

For some analyses, the community is the chosen unit of analysis. When this is the case, it means a sample size of seven intervention communities and seven comparison sites, which potentially limits statistical power. However, the Allies evaluation is unique in that it includes the evaluation of health outcomes across multiple communities, which allows for cross-coalition comparisons. In analyses conducted at the individual level, appropriate adjustments will be necessary to account for community-level clustering.

Strengths of the Allies evaluation are its duration and its comprehensiveness. Measurements of coalition formation and at several levels of outcome are taken. Measurements are quantitative and qualitative, and data generated by these methods are used as ends in themselves and as a way to confirm or inform other measures. Allies is employing measures used throughout a 5-year period, combining self-report and objective assessments, and employing a diverse array of instruments reflecting the varied perspectives of community stakeholders.

\section{CONCLUSION}

Evaluation designs for assessing a community coalition must balance measures of how coalitions do their work and evidence that the coalitions and those producing programs and interventions are making a difference. To become an established coalition, planning effective interventions that are relevant to the community and exploring whether the interventions made a difference are daunting tasks. The Allies coalitions have undertaken the challenge and wish to understand the impact of their efforts in creating new community capacities and improving health-related outcomes. It is possible that coalitions are not the answer to solving all communitywide health problems. The Allies evaluation effort strives to understand the contributions that coalitions make to asthma control above and beyond other initiatives in a community. It is hoped that the Allies evaluation experience will inform and assist others involved in similar work.

\section{REFERENCES}

Ayre, D., Clough, G., \& Norris, T. (2000). Facilitating community change. Boulder, CO: Grove Publishers.

Barbour, R. S. (1999). The case for combining qualitative and quantitative approaches in health services research. Journal of Health Services Research and Policy, 4(1), 39-43.

Beery, W. L., Brousseau, R., Cheadle, A., Greenwald, H. P., Pearson, D., Senter, S., et al. (2005). Evaluating the legacy of community health initiatives: A conceptual framework and example from the California Wellness Foundation's Health Improvement Initiative. Proceedings: Enhancing Community Capacity: California Healthy Cities and Communities Annual Conference. American Journal of Evaluation, 26(2), 150-165.

Berkowitz, B. (2001). Studying the outcomes of based coalitions. American Journal of Community Psychology, 29(2), 213-227. 
Bracht, N. (Ed.). (1990). Health promotion at the community level. Newbury Park, CA: Sage.

Brewer, J., \& Hunter, A. (1989). Multimethod research: A synthesis of styles. Newbury Park, CA: Sage.

Butterfoss, F. D., \& Francisco, V. T. (2004). Evaluating community partnerships and coalitions with practitioners in mind. Health Promotion Practice, 5(2), 108-114.

Butterfoss, F. D., Gilmore, L. A., Krieger, J. W., Lachance, L. L., Lara, M., Meurer J. R., et al. (2006). From formation to action: How Allies Against Asthma coalitions are getting the job done. Health Promotion Practice, 7(Suppl. 2), 34S-43S.

Butterfoss, F. D., Goodman, R. M., \& Wandersman, A. (1993). Community coalitions for prevention and health promotion. Health Education Research, 8(3), 315-330.

Butterfoss, F. D., Goodman, R. M., \& Wandersman, A. (1996). Community coalitions for prevention and health promotion: Factors predicting satisfaction, participation, and planning. Health Education Quarterly, 23(1), 65-79.

Butterfoss, F. D., \& Kegler, M. (2002). Toward a comprehensive understanding of community coalitions: Moving from practice to theory. In R. J. DiClemente, R. A. Crosby, \& M. C. Kegler (Eds.), Emerging theories in health promotion practice and research (pp. 157-193). San Francisco: Jossey-Bass.

Butterfoss, F. D., Lachance, L. L., \& Orians, C. E. (2006). Building Allies coalitions: Why formation matters. Health Promotion Practice, 7(Suppl. 2), 23S-33S.

Clark, N. M., Doctor, L. J., Friedman, A. R., Lachance, L. L., House, C. R., Houle, C. R., et al. (2006) Community coalitions to control chronic disease: Allies against asthma as a model and case study. Health Promotion Practice, 7(Suppl. 2), 14S-22S.

Clark, N. M., Feldman, C. H., Evans, D., Duzey, O., Levison, M. J., Wasilewski, Y., et al. (1986). Managing better: Children, parents, and asthma. Patient Education and Counseling, 8, 27-38.

COMMIT Research Group. (1995). Community Intervention Trial for Smoking Cessation (COMMIT): I. Cohort results from a four-year community intervention. American Journal of Public Health, 85(2), 183-192.

Denzin, N. (1970). Strategies of multiple triangulation. In N. Denzin (Ed.), The research act in sociology: A theoretical introduction to sociological method (pp. 345-360). New York: McGraw-Hill.

El-Askari, G., Freestone, J., Irizarry, C., Kraut, K. L., Mashiyama, S. T., Morgan, M. A., et al. (1998). The Healthy Neighborhoods Project: A local health department's role in catalyzing community development. Health Education \& Behavior, 25(2), 146-159.

Evans, R., Gergen, P. J., Mitchell, H., Kattan, M., Kercsmar, C., Crain, E., et al. (1999). A randomized clinical trial to reduce asthma morbidity among inner-city children: Results of the National Cooperative Inner-City Asthma Study. Journal of Pediatrics, 135(3), 332-338.

Farquhar, J. W., Fortman, S. P., Flora, J. A., Taylor, C. B., Haskell, W. L., Williams, P. T., et al. (1990). Effects of community-wide education on cardiovascular disease risk factors: The StanfordFiveCity Project. Journal of the American Medical Association, 264, 359-365.

Fawcett, S. B., Lewis, R. K., Paine-Andrews, A., Francisco, V. T., Richter, K. P., Williams, E. L., et al. (1997). Evaluating community coalitions for prevention of substance abuse: The case of Project Freedom. Health Education \& Behavior, 24(6), 812-828.
Fisher, E. B., Strunk, R. C., Sussman, L. K., Arfken, C., Sykes, R. K., Munro, J. F., et al. (1996). Acceptability and feasibility of a community approach to asthma management: The Neighborhood Asthma Coalition (NAC). Journal of Asthma, 33, 367-383.

Fisher, E. B., Strunk, R. C., Sussman, L. K., Sykes, R. K., \& Walker, M. S. (2004). Community organization to reduce the need for acute care for asthma among African American children in lowincome neighborhoods: The Neighborhood Asthma Coalition. Pediatrics, 114, 116-123.

Fisher, E. B., Sussman, L. K., Arfken, C., Harrison, D., Munro, J., Sykes, R. K., et al. (1994). Targeting high risk groups: Neighborhood organization for pediatric asthma management in the Neighborhood Asthma Coalition. Chest, 106, 248S-259S.

Foster-Fishman, P. G., Berkowitz, S. L., Lounsbury, D. W., Jacobson, S., \& Allen, N. A. (2001). Building collaborative capacity in community coalitions: A review and integrative framework. American Journal of Community Psychology, 29(2), 241-261.

Goodman, R. M., Wandersman, A., Chinman, M., Imm, P., \& Morrisey, E. (1996). An ecological assessment of community-based interventions for prevention and health promotion: Approaches to measuring community coalitions. American Journal of Community Psychology, 24(1), 33-61.

Green, L. W. (1992). PATCH: CDC's Planned Approach to Community Health: An application of PRECEED and an inspiration for PROCEED. Journal of Health Education, 23(3), 140-147.

Juniper, E. F., Guyatt, G. H., Feeny, D. H., Ferrie, P. J., Griffith, L. E., \& Townsend, M. (1996). Measuring quality of life in the parents of children with asthma. Quality of Life Research, 5, 27-34.

Kegler, M. C., Steckler, A., McLeroy, K., \& Malek, S. H. (1998). Factors that contribute to effective community health promotion coalitions: A study of 10 Project ASSIST coalitions in North Carolina. Health Education \& Behavior, 25(3), 338-353.

Kegler, M. C., Twiss, J. M., \& Look, V. (2000). Assessing community change at multiple levels: The genesis of an evaluation framework for the California Healthy Cities Project. Health Education \& Behavior, 27, 760-779.

Kelly, C. S., Meurer, J. R., Lachance, L. L., Taylor-Fishwick, J. C., Geng, X., \& Arabia, C. (2006). Engaging health care providers in coalition activities. Health Promotion Practice, 7(Suppl. 2), 66S-75S. Kenney, E., \& Sofaer, S. (2000). The Coalition Self Assessment Survey: A manual for users. New York: City University of New York, Baruch College, School of Public Affairs.

Koepsell, T. D., Martin, D. C., Diehr, P. H., Psaty, B. M., Wagner, E. H., Perrin, E., et al. (1991). Data analysis and sample size issues in evaluations of community-based health promotion and disease prevention programs: A mixed model analysis of variance approach. Journal of Clinical Epidemiology, 44(7), 701-713.

Koepsell, T. D., Wagner, E. H., Cheadle, A. D., Patrick, D. L., Martin, D. C., Diehr, P. H., et al. (1992). Selected methodological issues in evaluating community-based health promotion and disease prevention programs. Annual Review of Public Health, 13, 31-57.

Kreuter, M. W., Lezin, N. A., \& Young, L. A. (2000). Evaluating community-based collaborative mechanisms: Implications for practitioners. Health Promotion Practice, 1(1), 49-63.

Krieger, J. W., Bourcier, E., Doctor, L., Taylor-Fishwick, J. C., Lara, M., Peterson, J. W., et al. (2006). Integrating asthma prevention and control: The roles of the coalition. Health Promotion Practice, 7(Suppl. 2), 127S-138S. 
KU Work Group on Health Promotion and Community Development. (2000). Toolkits: Develop strategic and action plans. Lawrence: University of Kansas. Retrieved October 24, 2004, from http://ctb.ku.edu/tools/tk/en/tools_tk_content_page_193.jsp

Kumpfer, K., Turner, C., Hopkins, R., \& Librett, J. (1993). Leadership and team effectiveness in community coalitions for the prevention of alcohol and other drug abuse. Health Education Research: Theory and Practice, 8(3), 359-374.

Lasker, R. D., \& Weiss, E. S. (2003). Broadening participation in community problem solving: A multidisciplinary model to support collaborative practice and research. Journal of Urban Health: Bulletin of the New York Academy of Medicine, 80(1), 14-47.

Lasker, R. D., Weiss, E. S., \& Miller, R. (2001). Partnership synergy: A practical framework for studying and strengthening the collaborative advantage. Milbank Quarterly, 79, 179-206.

McLeroy, K. R., Kegler, M. C., Steckler, A., Burdine, J. M., \& Wisotzky, M. (1994). Community coalitions for health promotion: Summary and further reflections. Health Education Research, 9(1), 1-11.

McLeroy, K. R., Norton, B. L., Kegler, M. C., Burdine, J. N., \& Sumaya, C. V. (2003). Community-based interventions. American Journal of Public Health, 93(4), 529-533.

Merzel, C., \& D’Afflitti, J. (2003). Reconsidering community-based health promotion: Promise, performance, and potential. American Journal of Public Health, 93(4), 557-574.

Mittelmark, M. B., Luepker, R. V., Jacobs, D. R., Bracht, N. F., Carlaw, R. W., Crow, R., et al. (1986). Community-wide prevention of cardiovascular disease: Education strategies of the Minnesota Heart Health Program. Preventive Medicine, 15(1), 1-17.

Patton, M. Q. (2001). Qualitative research and evaluation methods. Thousand Oaks, CA: Sage.
Peterson, J. W., Butterfoss, F. D., Nicholas, E. A., Gilmore, L. A., Lara, M., \& Lachance, L. L. (2006). Engaging the community in coalition efforts to address childhood asthma. Health Promotion Practice, 7(Suppl. 2), 56S-65S.

Rose, G. (1992). The strategy of preventive medicine. New York: Oxford University Press.

Rosenthal, M. P., Butterfoss, F. D., Doctor, L., Gilmore, L. A., Krieger, J. W., Meurer, J. R., et al. (2006). The coalition process at work: Building care coordination models to control chronic disease. Health Promotion Practice, 7(Suppl. 2), 117S-126S.

Roussos, S. T., \& Fawcett, S. B. (2000). A review of collaborative partnerships as a strategy for improving community health. Annual Review of Public Health, 21, 369-402.

Sandelowski, M. (2000). Combining qualitative and quantitative sampling, data collection and analysis techniques in mixed-methods studies. Research in Nursing and Health, 23, 246-255.

Schlaff, A. L. (1991). Boston's Codman Square Community Partnership for Health Promotion. Public Health Reports, 106(2), 186-191.

Tarlow, A. R., Kehrer, B. H., Hall, D. P., Sammuels, S. E., Brown, G. S., Felix, M. R., et al. (1987). Foundation work: The health promotion program on the Henry J. Kaiser Family Foundation. American Journal of Health Promotion, 2, 74-80.

Wallerstein, N. (1999). Power between evaluator and community: Research relationships within New Mexico's healthier communities. Social Science and Medicine, 49(1), 39-53.

Winer, M., \& Ray, K. (2000). Collaboration handbook: Creating, sustaining, and enjoying the journey. Minneapolis, MN: Amherst H. Wilder Foundation.

Wolff, T. (2001). A practitioner's guide to successful coalitions. American Journal of Community Psychology, 29(2), 173-191. 